\title{
Insidensi Kista Duktus Tiroglosus di Bagian Bedah RSUP Prof. Dr. R. D. Kandou Manado Periode Januari 2014 - Desember 2016
}

\author{
${ }^{1}$ Meidina Kinontoa \\ ${ }^{2}$ Nico Lumintang \\ ${ }^{2}$ Andriessanto C. Lengkong
}

\author{
${ }^{1}$ Program Studi Pendidikan Dokter Fakultas Kedokteran Universitas Sam Ratulangi Manado \\ ${ }^{2}$ Bagian Bedah Fakultas Kedokteran Universitas Sam Ratulangi Manado \\ Email: meidinakinontoa@gmail.com
}

\begin{abstract}
Thyroglossal duct cyst is the most common asymptomatic congenital mass found in the neck region. It is more commonly occurs in pediatric patients but not uncommon in adult patients. According to epidemiologic data, there is no difference in predilection among sexes. Diagnosis of thyroglossal duct cyst is ascertained by anamnesis, physical examination, and ancillary examination. Treatment of thyroglossal duct cyst is surgery. This study was aimed to establish the incidence of thyroglossal duct cysts at the Surgery Department of Prof. Dr. R. D. Kandou Hospital Manado in the period of January 2014 - December 2016 based on age, gender, surgical treatment, as well as the location of thyroglossal duct cysts. This was a descriptive retrospective study using all thyroglossal duct cyst medical records at the Surgery Department of Prof. Dr. R. D. Kandou Hospital Manado in the period of January 2014December 2016. The results showed that the highest incidence of thyroglossal duct cyst was in 2014 (37\%), and in the age group of 6-11 years old. Male patients were more common than females. Meanwhile, the most common locations of this cyst were suprahyoid and subhyoid (25\%) and the most common surgical procedure used was modified Sistrunk (88\%). Conclusion: Thyroglossal duct cyst was more common in age group of 6-11 years, males, suprahyoid and subhyoid locations, and treated with modified Sistrunk surgery
\end{abstract}

Keywords: thyroglossal duct cyst

\begin{abstract}
Abstrak: Kista duktus tiroglosus merupakan massa kongenital asimtomatik yang paling sering ditemukan di daerah leher. Kasus ini lebih sering terjadi pada anak tetapi juga tidak jarang ditemukan pada orang dewasa. Secara epidemiologi tidak ada perbedaan predileksi jenis kelamin antara laki-laki dan perempuan. Diagnosis kista duktus tiroglosus ditegakkan berdasarkan anamnesis, pemeriksaan fisik dan pemeriksaan penunjang. Penatalaksanaan dari kista duktus tiroglosus adalah tindakan pembedahan. Penelitian ini bertujuan unuk mengetahui insidensi kista duktus tiroglosus di Bagian Bedah RSUP Prof. Dr. R. D. Kandou Manado periode Januari 2014-Desember 2016, berdasarkan tahun, usia, jenis kelamin, tindakan pembedahan, serta letak kista duktus tiroglosus. Jenis penelitian ialah deskriptif retrospektif dengan menggunakan semua data rekam medik pasien kista duktus tiroglosus di Bagian Bedah RSUP Prof. Dr. R. D. Kandou Manado periode Januari 2014-Desember 2016. Hasil penelitian menunjukkan bahwa insidensi kista duktus tiroglosus selama periode Januari 2014-Desember 2016 tertinggi pada tahun 2014 (37\%) dan pada kelompok usia 6-11 tahun (37\%). Jumlah pasien laki-laki ditemukan lebih banyak daripada perempuan. Letak kista tersering ditemukan di suprahioid dan subhioid (25\%) dan tindakan pembedahan yang tersering dilakukan ialah modifikasi Sistrunk (88\%). Simpulan: Kista tiroglosus paling sering ditemukan pada kelompok usia 6-11 tahun, jenis kelamin laki-laki, dengan letak kista suprahiod dan subhiod, serta tindakan pembedahan modifikasi Sistrunk.
\end{abstract}

Kata kunci: kista duktus tiroglosus 
Kista duktus tiroglosus adalah massa kongenital asimtomatik yang paling sering ditemukan di daerah leher (7\%). ${ }^{1}$ Kista duktus tiroglosus dapat terjadi di sepanjang saluran tiroglosus, dengan $70 \%$ timbul di garis tengah anterior leher, di bawah tulang hyoid. ${ }^{2}$ Kasus kista duktus tiroglosus biasanya didiagnosis di usia muda tapi juga tidak jarang ditemukan pada orang dewasa. ${ }^{3}$ Secara epidemiologi tidak ada perbedaan predileksi jenis kelamin antara laki-laki dan perempuan. $^{4,5}$

Kista duktus tiroglosus merupakan kasus terbanyak dari massa non neoplastik di leher, mencakup 40\% dari tumor primer di daerah leher. Dikatakan hampir 70\% dari seluruh kista di leher ialah kista duktus tiroglosus. $^{6}$

Kasus ini lebih sering terjadi pada anak-anak, walaupun dapat ditemukan di semua usia. Predileksi usia terbanyak ialah 0-20 tahun (52\%), dan usia sampai 5 tahun sebesar 38\%. Sistrunk (1920) melaporkan 31 kasus dari 86.000 pasien anak. Tidak terdapat perbedaan risiko terjadinya kista berdasarkan jenis kelamin dan usia; bisa didapat dari lahir sampai 70 tahun, dengan rerata usia 5,5 tahun. ${ }^{7-8}$ Peneliti lain melaporkan predileksi usia kurang dari 10 tahun sebesar $31,5 \%$, pada dekade ke dua $20,4 \%$, dekade ke tiga $13,5 \%$, dan usia lebih dari 30 tahun sebesar 34,6\%. Waddell mendapatkan 28 kasus kista duktus tiroglosus secara histologik dari 61 pasien yang diduga kista tersebut. ${ }^{9}$

Diagnosis kista duktus tiroglosus ditegakkan berdasarkan anamnesis, pemeriksaan fisik, dan pemeriksaan penunjang. Diagnosis pasti ditegakkan dengan pemeriksaan histopatologik. ${ }^{10-13}$

Penatalaksanaan kista duktus tiroglosus ialah dengan tindakan pembedahan karena bila dibiarkan kista tersebut dapat mengalami komplikasi berupa infeksi. Tindakan yang dilakukan dapat berupa eksisi sederhana atau prosedur Sistrunk. Rekurensi dari kista duktus tiroglosus setelah eksisi lengkap dengan prosedur Sistrunk dilaporkan sebesar 2,6-5\% sedangkan pada eksisi kista dengan cara sederhana hasilnya menunjukkan tingkat rekurensi yang lebih tinggi yaitu $37-70 \% .^{2}$ Oleh karena itu prosedur Sistrunk menjadi pilihan dibandingkan dengan eksisi sederhana agar dapat mengurangi tingkat rekurensi.

Insidensi karsinoma yang berasal dari kista duktus tiroglosus hanya muncul sekitar 1\% dari seluruh kasus kista duktus tiroglosus. Faktor risiko yang berperan dalam terjadinya karsinoma, antara lain riwayat terpapar radiasi, riwayat penyakit tiroid, usia, ukuran tumor, penyebaran tumor, dan faktor histopatologik. ${ }^{14}$

\section{METODE PENELITIAN}

Jenis penelitian ini ialah deskriptif retrospektif pada pasien kista duktus tiroglosus di Bagian Bedah RSUP Prof. Dr. R. D. Kandou Manado. Subjek penelitian ialah semua data rekam medik pasien kista duktus tiroglosus di Bagian Bedah RSUP Prof. Dr. R. D. Kandou Manado periode Januari 2014 - Desember 2016. Variabel penelitian ialah tahun, usia, jenis kelamin, tindakan pembedahan, dan letak kista.

\section{HASIL PENELITIAN}

Dari hasil penelitian secara deskriptif retrospektif yang dilakukan di bagian Bedah dan Bagian Rekam Medik RSUP Prof. Dr. R. D. Kandou Manado selama periode Januari 2014 s/d Desember 2016, terdapat 12 penderita dengan diagnosis utama kista duktus tiroglosus namun yang tersedia dan lengkap hanya 8 data pasien.

Tabel 1 memperlihatkan insidensi kista duktus tiroglosus di Bagian Bedah RSUP Prof. Dr. R. D. Kandou Manado selama periode Januari 2014 s/d Desember 2016, yaitu 3 kasus (19\%) pada tahun 2014, 2 kasus (12\%) pada tahun 2015, dan 3 kasus (19\%) pada tahun 2016.

Tabel 1. Distribusi penderita kista duktus tiroglosus berdasarkan tahun

\begin{tabular}{ccc}
\hline Tahun & Jumlah pasien & Persentase \\
\hline 2014 & 3 & $37 \%$ \\
2015 & 2 & $25 \%$ \\
2016 & 3 & $38 \%$ \\
Total & 8 & $100 \%$ \\
\hline
\end{tabular}


Tabel 2 menampilkan pada kelompok usia 0-5 tahun terdapat 2 pasien (25\%), kelompok usia 6-11 tahun terdapat 3 pasien (37\%), kelompok usia 17-25 tahun terdapat 1 pasien (13\%), kelompok usia 26-35 tahun terdapat 1 pasien (13\%), dan kelompok usia 36-45 tahun terdapat 1 pasien (13\%).

Tabel 2. Distribusi pasien kista duktus tiroglosus berdasarkan usia

\begin{tabular}{ccc}
\hline Usia (Tahun) & $\begin{array}{c}\text { Jumlah } \\
\text { pasien }\end{array}$ & $\begin{array}{c}\text { Persentase } \\
(\%)\end{array}$ \\
\hline $0-5$ & 2 & $25 \%$ \\
$6-11$ & 3 & $37 \%$ \\
$17-25$ & 1 & $13 \%$ \\
$26-35$ & 1 & $13 \%$ \\
$36-45$ & 1 & $13 \%$ \\
Total & 8 & $100 \%$ \\
\hline
\end{tabular}

Tabel 3 menunjukkan dari total 8 pasien, terdapat sebanyak 5 orang (62\%) berjenis kelamin laki-laki dan 3 orang (38\%) berjenis kelamin perempuan.

Tabel 3. Distribusi pasien kista duktus tiroglosus berdasarkan jenis kelamin

\begin{tabular}{cccc}
\hline \multirow{2}{*}{ Tahun } & \multicolumn{2}{c}{ Jenis kelamin } & \multirow{2}{*}{ Total } \\
\cline { 2 - 3 } & Laki-laki & Perempuan & \\
\hline 2014 & 2 & 1 & 3 \\
2015 & 1 & 1 & 1 \\
2016 & 2 & 1 & 3 \\
Total & 5 & 3 & 8 \\
& $(62 \%)$ & $(38 \%)$ & $(100 \%)$ \\
\hline
\end{tabular}

Tabel 4 memperlihatkan bahwa dari total 8 pasien, didapatkan tindakan prosedur Sistrunk pada 1 pasien perempuan (12\%), sedangkan pada laki-laki yang terbanyak ialah modifikasi Sistrunk (88\%).

Tabel 4. Distribusi penderita kista duktus tiroglosus berdasarkan tindakan pembedahan

\begin{tabular}{cccc}
\hline Tindakan & \multicolumn{2}{c}{ Jenis kelamin } & Total \\
\cline { 2 - 3 } pembedahan & Laki-laki & Perempuan & \\
\hline $\begin{array}{c}\text { Prosedur } \\
\text { Sistrunk }\end{array}$ & 0 & 1 & $1(12 \%)$ \\
$\begin{array}{c}\text { Modified } \\
\text { Sistrunk } \\
\text { Total }\end{array}$ & 5 & 2 & $7(88 \%)$ \\
\hline
\end{tabular}

Tabel 5 memaparkan distribusi pasien kista duktus tiroglosus berdasarkan letak kista. Terdapat 2 pasien (25\%) dengan letak kista di suprahioid, 2 pasien (25\%) dengan letak kista di infrahioid, 1 pasien (12\%) dengan lokasi kista di jukstahioid, 1 pasien (12\%) dengan letak kista di intralingual, 1 pasien (13\%) dengan letak kista di intralaringeal, dan 1 pasien (13\%) dengan letak kista di suprasternal.

Tabel 5. Distribusi kista duktus tiroglosus berdasarkan letak kista

\begin{tabular}{ccc}
\hline Letak kista & $\begin{array}{c}\text { Jumlah } \\
\text { kasus }\end{array}$ & Persentase \\
\hline Suprahioid & 2 & $25 \%$ \\
Infrahioid & 2 & $25 \%$ \\
Jukstahioid & 1 & $12 \%$ \\
Intralingual & 1 & $12 \%$ \\
Intralaringeal & 1 & $13 \%$ \\
Suprasternal & 1 & $13 \%$ \\
Total & 8 & $100 \%$ \\
\hline
\end{tabular}

\section{BAHASAN}

Sampel yang diteliti ialah pasien kista duktus tiroglosus berdasarkan diagnosis yang tertera dalam rekam medik periode Januari 2014-Desember 2016 di Bagian Bedah RSUP Prof. Dr. R. D. Kandou Manado. Didapatkan 8 kasus dalam kurun waktu tersebut dnegan terbanyak pada tahun 2016 yaitu 3 kasus (38\%).

Hasil distribusi pasien kista duktus tiroglosus berdasarkan kelompok usia mendapatkan terbanyak pada kelompok usia 611 tahun sebesar 37\% disusul oleh kelompok usia 0-4 tahun sebesar 25\%, sedangkan untuk kelompok usia 17-25 tahun, 26-35 tahun, dan 36-45 tahun, masing-masing sebanyak 13\%. Kista duktus tiroglosus biasanya muncul pada anak-anak dan remaja. ${ }^{15}$ Sekitar $50 \%$ ditemukan pada usia 2-10 tahun, 10\% antara usia 15-20 tahun, dan beberapa muncul pada usia lanjut tetapi biasanya sebelum usia 30 tahun. ${ }^{16}$

Hasil distribusi pasien kista duktus tiroglosus berdasarkan jenis kelamin mendapatkan sebanyak 5 pasien laki-laki (62\%) dan 3 pasien perempuan (38\%) dari total 8 pasien selama periode Januari 2014Desember 2016. Data ini menunjukkan 
kasus kista duktus tiroglosus lebih banyak pada jenis kelamin laki-laki dibandingkan perempuan tapi untuk kasus kista duktus tiroglosus walaupun menurut acuan pustaka tidak terdapat perbedaan predileksi jenis kelamin. ${ }^{7,8}$

Hasil distribusi pasien kista duktus tiroglosus berdasarkan tindakan pembedahan yang dilakukan di Bagian Bedah RSUP Prof Dr. R. D. Kandou Manado periode Januari 2016-Desember 2016 didapatkan tindakan operatif sebanyak 8 pasien (100\%) sedangkan untuk tindak non-operatif tidak ada (0\%). Tindakan operatif yang dilakukan yaitu modifikasi Sistrunk dan prosedur Sistrunk. Hal ini sesuai dengan acuan pustaka yang menyatakan prosedur ini dapat menurunkan angka rekurensi sampai sekitar 4\%; jadi untuk teknik pembedahan dengan metode Sistrunk merupakan pilihan yang tepat. ${ }^{17}$

Hasil distribusi pasien kista duktus tiroglosus berdasarkan letak kista, paling sering terletak di suprahioid dan infrahioid (25\%), disusul oleh suprasternal dan intralaringeal (masing-masing 13\%), kemudian jukstahioid dan intralingual (masing-masing 12\%). Kista duktus tiroglosus dapat tumbuh dimana saja di garis tengah leher, sepanjang jalur bebas duktus tiroglosus mulai dari dasar lidah sampai ismus tiroid. ${ }^{6}$ Penelitian yang dilakukan Bailey ${ }^{18}$ melaporkan dari hasil survei terhadap 92 kasus didapatkan posisi kista yag berbeda sepanjang saluran tiroglosus, paling banyak terletak di suprahioid, disusul subhioid, intralingual dan intralaringeal.

\section{SIMPULAN}

Kista tiroglosus paling sering didapatkan pada kelompok usia 6-11 tahun, jenis kelamin laki-laki, dengan letak kista suprahiod dan subhiod serta tindakan pembedahan modifikasi Sistrunk.

\section{SARAN}

Disarankan untuk dilakukan perbaikan dalam penyimpanan, penyusunan, serta kelengkapan data rekam medik pasien di RSUP Prof. Dr. R. D. Kandou Manado

\section{DAFTAR PUSTAKA}

1. Kurt A, Ortug C, Aydar Y, Ortug G. An incidence study on thyroglossal duct cysts in adults. Saudi Med J. 2007; 28(4):593-7.

2. Bouquot JE. Thyroglossal duct cyst. The Maxillofacial Center for Diagnostics \& Research [internet]. 2017 [cited 2017 July 17]. Available from: http://www. maxillofacialcenter.com/Bondbook/soft issue/thyroglossalcyst.html\#Quick

3. Baisakhiya N. Giant thyroglossal cyst in an elderly patient. Indian J Otolaryngol Head Neck Surg. 2011;63(1):27-8.

4. Probst R, Grevers G, Iro H. Basic Otorhinolaryngology. New York: Thieme, 2006.

5. Clarke P. Benign neck disease: In: Gleeson M, penyunting. Scott's Brown's Otolaryngology Head and Neck Surgery (7th ed). Great Britain: Hodder Arnold, 2008; p. 1777-8.

6. Sobol M. Benign tumors. In: Thawley S, Panje WR, editors. Comprehensive Management of Head and Neck Tumors Vol. 2. Philadelphia: WB Saunders, 2005; p. 1362-9.

7. Ballenger JJ. Penyakit Telinga, Hidung, Tenggorok, Kepala, dan Leher Jilid 1 (13th ed). Alih Bahasa: Staf Pengajar Bag. THT FKUI. Jakarta: Bina Rupa Aksara, 2006; p. 295-6, 381-2.

8. Cohen JI. Massa jinak leher. In: Boies Buku Ajar Penyakit THT (6th ed). Alih Bahasa: Wijaya C. Jakarta: EGC, 2008; p. $415-21$.

9. Montgomery WW. Surgery of the Upper Respiratory System Vol. II (2nd ed). Philadelphia: Lea \& Febiger, 2005; p. 88.

10. Slough CM, Dralle $H$, Machens A, Randolph GW. Diagnosis and treatment of thyroid and parathyroid disorders. In: Bailey BJ, Johnson JT, Newlands SD, editors. Head and Neck Surgery Otolaryngology (4th ed). Texas: Lippincot William \& Wilkins, 2006; p. 1630-55.

11. Swaid Al, Al-Amar AY. Management of thyroglossal duct cyst. The Open Otorhinolaryngology Journal. 2008;2: 26-8.

12. Islam O, Naul GL. Thyroglossal duct cyst. Diperbaharui 19 September 2013. [cited 2017 July 17]. Available from: 
URL: http://emedicine.medscape.com/ article/1346365-overview.

13. Acierno SP, Waldhausen JH. Congenital cervical cysts, sinuses and fistulae. Otolaryngol Clin North Am. 2007; 40(1):161-76.

14. Kazemi M, Assadi M, Kazemi AA, Ghazvini LA. Primary Papillary carcinoma in thyroglossal duct cyst. Hell J Nucl Med. 2006;9(1):39-40.

15. Anderson W. Pathology for the Surgeon (8th ed). Philadelphia: Kothari Book Depot, 1969; p. 135.
16. Sjamjuhidat R, Jong WD. Buku Ajar Ilmu Bedah (Edisi Revisi). Jakarta: EGC, 1996; p. 499-500, 929.

17. Wright ST, Newlands S. Embriology of the Neck and Neck Masses. Grand Rounds Presentation. Texas: Department of Otolaryngology The University of Texas; 2005.

18. Bailey H. Demonstration of Physical Signs in Clinical Surgery (10th edition):. Baltimore: Williams \& Wilkins, 2000; p. 105-6 